\title{
PEMETAAN STRUKTUR LUAR KAMPUNG KOTA TANJUNG GEDONG
}

\author{
Fermanto Lianto $^{1}$, Rudy Trisno ${ }^{2}$, Mieke Choandi ${ }^{3}$, dan Denny Husin ${ }^{4}$ \\ ${ }^{1}$ Jurusan Arsitektur dan Perencanaan, Universitas Tarumanagara, Jakarta \\ Email: fermantol@ft.untar.ac.id \\ 2 Jurusan Arsitektur dan Perencanaan, Universitas Tarumanagara, Jakarta \\ Email: rudyt@ft.untar.ac.id \\ ${ }^{3}$ Jurusan Arsitektur dan Perencanaan, Universitas Tarumanagara, Jakarta \\ Email: mieke@ft.untar.ac.id \\ ${ }^{4}$ Jurusan Arsitektur dan Perencanaan, Universitas Tarumanagara, Jakarta \\ Email: denny@ft.untar.ac.id
}

\begin{abstract}
Kampung Tanjung Gedong is located at Tanjung Gedong lane. It is situated at the back of the educational area in Grogol, West of Jakarta. This kampung area is surrounded by the city's facilities, like the University of Tarumanagara, the University of Trisakti, the Sumber Waras Hospital, other residential and commercial areas. In terms of the urban fabric, this kampung is characterized by irregularity and informality. Its streets are varied in size, meandering in shapes and forming a semi-labyrinth environment. Its inhabitants are students, laborers, street vendors, traders, etc. Despite having moderate spatial quality, Kampung Tanjung Gedong requires an improvement to be able to adapt to its context. One of the most effective solutions is to improve the condition by providing its inhabitants with education. Related to architecture, a community engagement project is planned to transfer knowledge by using mapping as training. It is intended to stimulate a better understanding of its inhabitants regarding the potency of the space. The activity includes documentation, both as actualization and archive. The methods are manual and digital mappings, it is a combination of hand and digital sketching by using manual tools and digital instruments. The mapping process is supported by Autodesk cad and camera as the tools. Drawing in this sense is utilized as a media for discussion and presentation. The finding is a cross-checking method, re-examination as a process to re-check existing location against archive and photography. The result is a series of manual, digital, and graphic mappings of kampung Gedong's surface structure.
\end{abstract}

Keywords: city, kampung, mapping, structure, surface.

\begin{abstract}
ABSTRAK
Kampung Tanjung Gedong berlokasi di jalan Tanjung Gedong, terletak di belakang kawasan pendidikan Grogol Jakarta Barat. Kampung Tanjung Gedong merupakan area pendukung yang menyediakan kebutuhan kawasan pendidikan Jakarta Barat dan lingkungan sekitarnya. Area ini dikeliling parsel-parsel kawasan, seperti: Universitas Tarumanagara, Universitas Trisakti, Rumah Sakit Sumber Waras, perumahan dan area komersial di sekitarnya. Kampung Tanjung Gedong memiliki karakteristik fisik tidak selalu beraturan, dengan kondisi rumah yang tidak selalu tertata. Kondisi jalan kampung juga memiliki ukuran yang bervariasi dengan gang-gang yang berkelak-kelok. Pekerjaan penghuninya bermacam-macam dari yang berstatus: pekerja, mahasiswa, pedagang informal dan sebagainya. Meski hidup rukun dan damai, kondisi lingkungan dan ruang hidup mereka perlu terus ditingkatkan, agar dapat beradaptasi dengan kemajuan jaman. Salah satunya adalah dengan transfer ilmu ruang melalui pemetaan. Keilmuan dapat memberikan pemahaman atas potensi ruang dan lingkungan tempat tinggal mereka. Selain itu, pemetaan berguna sebagai dokumentasi dan aktualisasi peta eksisting, apalagi transformasi struktur kampung dikategorikan terjadi sangat cepat. Pemetaan dilakukan dengan 2 metode manual dan digital. Sementara metode manual dilakukan melalui sketsa, metode digital dilakukan dengan cara tracing menggunakan autodesk cad. Gambar dijadikan sebagai bahasa komunikasi pada sebuah lokasi sampel: sebuah hasil observasi, diskusi dan dokumentasi. Tujuan kegiatan ini adalah memanfaatkan proses menggambar menjadi sarana pelatihan, sementara visualisasi dapat berguna juga sebagai dokumentasi. Temuannya adalah kedua metode saling melengkapi sebagai alat pertukaran informasi, dan memungkinkan pemeriksaan kembali (cross-checking) pada proses pemetaan. Hasil akhir berupa peta manual, peta pola, peta digital dan peta grafis untuk mempresentasikan keruangan kampung.
\end{abstract}

Kata kunci: kampung, kota, luar, pemetaan, struktur. 


\section{PENDAHULUAN}

Kondisi kampung kota tidak selalu dalam keadaan teratur dan sehat (Darmawan \& Utami, 2018). Sebagian dari kampung kota khususnya di Jakarta dinilai kumuh dan tidak layak, dianggap tidak terencana dan tidak tertata. Meski demikian, kampung kota tidak selalu identik dengan stigma negatif. Sebagian besar kampung kota sebenarnya merupakan rumah-rumah penduduk asli atau pendatang, dengan pengetahuan seadanya mereka membangun ruang hidup (Sihombing, 2014). Wajar pula bila sebagian dari awam melihat kampung tidak selalu indah dipandang mata, karena mayoritas kaum intelektual menyenyam pendidikan formal yang didominasi oleh perspektif modern yang bersifat kontras dengan wawasan pengetahuan warga kampung kota (Ambarwati \& Johan, 2016). Sebuah kegiatan pengabdian kepada masyarakat menyatukan perbedaan perspektif ini. Pemetaan kampung kota berpotensi memberikan kontribusi pengetahuan keruangan kepada masyarakat kampung (Siswanto, et al., 2018) dengan tujuan membangun potensi.

Kampung kota tidak selalu kumuh, beberapa kampung bahkan kaya secara budaya, sosial atau ekonomi. Banyak kampung terbukti suskses sebagai aset wisata atau produktif bagi kotanya. Sebut saja Kampung Pelangi, Kampung Hijau, Kampung Nelayan, Kampung Inggris, Kampung Cyber yang telah melalui sebuah proses perbaikan, perencanaan dan penataan kreatif. Kebijakan dan perencanaan yang baik telah menyulap kampung-kampung kota yang sederhana menjadi kampung yang istimewa dan unik (Setyawan, et al., 2018). Namun demikian, kondisi kampung-kampung ini tidak secara segera berubah begitu saja. Kampung-kampung tersebut telah melalui rangkaian proses panjang dan mendapat perhatian khusus, sehingga berkesempatan untuk menata diri dan bertransformasi (Siswanto, et al., 2018).

Untuk memulai sebuah proses perbaikan dan perencanaan pada kampung membutuhkan tahapan inisiasi. Salah satu usaha untuk memulainya adalah dengan melakukan pemetaan. Pemetaan tidak saja ditujukan sebagai aktualisasi, namun juga komunikasi dan strategi untuk menjalin kerjasama dengan warga kampung. Pemetaan struktur luar kampung Tanjung Gedong bertujuan untuk melakukan perekaman terhadap ruang kampung yang bersifat fundamental, sementara dimanfaatkan sebagai ajang transfer keilmuan. Sampel peta dilakukan hanya pada area tertentu agar tidak mengganggu privasi ruang internal. Area yang digagas adalah area penting di daerah Mesjid At-Taufiq Jami, sebuah fasilitas ibadah yang sekaligus menjadi salah-satu landmark jalan Tanjung Gedong. Landmark dianggap krusial dalam pemilihan lokasi karena bagi warga kampung berfungsi sebagai penanda dan tempat berkumpul (Maharani, et al., 2017). Pemetaan struktur luar menjadi sebuah rangkaian proses penggambaran dan pengukuran aktual pada kondisi fisik struktur luar kampung. Aktivitas dilaksanakan dalam rentang waktu 6 bulan saat kegiatan dilakukan, sebuah rekaman fisik bersifat terbatas mengingat sifat kampung yang temporer.

Pemetaan ini berpotensi memberikan pengetahuan keruangan, sekaligus menyuguhkan rekaman terhadap ruang hidup mereka. Pemetaan ini dapat digunakan sebagai patokan atau arahan pengembangan, bila sekiranya dibutuhkan oleh lingkungan (Samhudi, 2015). Kegiatan pemetaan juga bermaksud untuk mengawali kerjasama dengan warga dan area Tanjung Gedong secara keseluruhan. Proses pemetaan adalah usaha pengembangan kampung sebagai lokasi strategis berkembangnya sektor informal, yang selama ini mendukung kebutuhan warga kampus dan sekitarnya. Pemetaan terhadap jalan Tanjung Gedong berguna juga untuk memperoleh data atas tatanan, ruang sisa, ruang potensial, ruang hijau dan ruang-ruang bersama (Wijaya, et al., 2018). Pemetaan struktur luar mengedepankan penggambaran berdasar atas pengalaman dalam kampung, dengan menekankan pada koridor sebagai struktur kampung, sebuah ruang bersama yang bersifat fundamental untuk keseharian mereka (Ambarwati \& Johan, 2016). 


\section{METODE DAN MATERIAL}

Pemetaan struktur luar dilakukan dengan metode kualitatif dengan mengkombinasi visualisasi foto dan penggambaran diagram (Gambar 1). Proses ini dilakukan dengan cara:

1. Melakukan dokumentasi dengan foto/ video.

Pemotretan dilakukan untuk merekam: pengalaman dalam kampung, tampak dan struktur luar kampung.

2. Mencocokkan peta dan meletakkan dasar pada archive atau data lama.

Peta eksisting, archive dan google dicocokkan dengan sketsa aktual (Isnaini, 2015).

3. Melakukan observasi lapangan.

Kunjungan, survey dan komunikasi.

4. Melakukan pengukuran langsung terhadap struktur luar.

Pengukuran dilakukan dengan alat meteran, proporsi dengan dimensi tubuh dan modul material untuk pengecekan.

5. Menggambarkan peta secara manual dan digital.

Sketsa manual dengan pensil dan pen, sementara gambar digital menggunakan autodesk.

6. Melakukan transfer dengan software lain misalnya Adobe Illustrator CS, Adobe Photoshop.

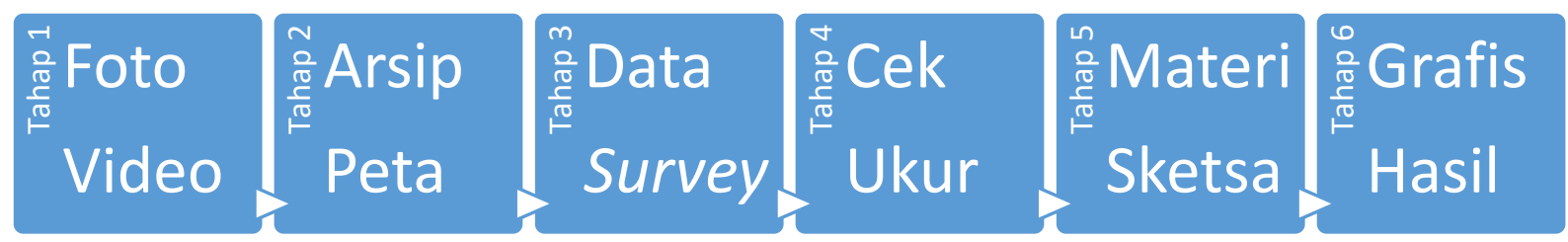

Gambar 1. Metode dan Tahapan Pemetaan

Visualisasi dilakukan untuk meningkatkan kualitas grafis peta dan presentasi spesifik. Aspekaspek berikut ditekankan untuk menghasilkan pemetaan struktur luar:

a. Photography.

Dokumentasi awal diawali dengan memperoleh foto-foto awal sebagai rekaman terhadap kondisi terbaru, foto-foto dapat berguna untuk membandingkan kondisi bila terjadi perubahan di kemudian hari. Foto juga dapat berguna untuk mencocokkan kondisi fisik dengan peta yang dibuat sebagai data tersier.

b. Tracing Map.

Melakukan rekam jejak pada pemetaan. Teknik mencocokkan dan melakukan pengaktualisasian gambar peta dilakukan, yakni dengan cara: penyandingan gambar, kegiatan melengkapi, memperbaiki/revisi gambar peta berdasarkan peta lama, archive, peta dari pemerintah atau peneliti lain untuk mendapatkan gambaran yang lebih presisi.

c. Focus Group Discussion.

Melakukan diskusi terhadap tim internal, termasuk wawancara, survey, dan mengumpulkan data di lapangan untuk didiskusikan dengan warga bila dibutuhkan.

d. Digital Printing.

Pencetakan digital untuk menghasilkan luaran fisik, hasil menargetkan file digital yang dapat diperbanyak atau dicetak dengan berbagai media untuk kebutuhan beragam. Standar hasil akhir yang diproduksi sebagai keluaran adalah pemetaan yang dapat dicetak di atas kertas HVS dengan berbagai skala dan ketebalan sesuai kebutuhan.

e. Media studi

Media studi didominasi mayoritas oleh bahan turunan kertas, baik: hvs, karton, birmet, kardus untuk kebutuhan baik modeling, diagram, presentasi, brosur, leaflet dan poster. 


\section{HASIL DAN PEMBAHASAN}

Kampung Tanjung Gedong telah bertransformasi menjadi tempat yang strategis tidak saja untuk tinggal, namun juga untuk mencari nafkah. Area kampung Tanjung Gedong telah menjadi satu dengan kawasan urbannya dan telah menjadi lokasi alternatif untuk memperoleh kebutuhan seharihari dengan harga terjangkau. Lepas dari kondisi kampung yang kini telah bertransformasi, masih banyak warganya yang tidak memiliki pengetahuan keruangan. Belum lagi letak strategis kampung belum memiliki dokumentasi dan rekaman memadai. Pemetaan sangat penting untuk memberikan pemahaman keruangan bagi warga kampung. Perubahan fisik kampung yang cepat berubah dan potensi kampung sebagai sumber daya keruangan perlu dipetakan sebagai upaya membantu pengembangan lingungan. Pengembangan inilah yang nantinya dapat dapat membawa kampung sejajar dengan kotanya.

Pemetaan kampung untuk kebutuhan warga kampung, jelas berbeda dengan pemetaan kota pada umumnya. Pemetaan kampung ditujukan untuk memberikan wawasan tentang gambar keruangan dan pemanfaatan kampung, selain sebagai proses dokumentasi. Proses pembuatan peta untuk warga kampung perlu dilakukan melalui sudut pandang dari dalam kampung dan dilaksanakan secara bertahap agar mudah dipahami warganya. Secara umum pemetaan kampung dibagi menjadi dua: yakni penggambaran peta manual dan digital. Hal ini dimaksudkan agar proses pemetaan dapat dijadikan sebagai cara untuk menghubungkan rentang pengetahuan warga kampung dengan awam maupun intelektual. Proses awal diinisiasi dengan mempelajari peta yang tersedia dan dapat diakses oleh umum, setelah itu dilakukanlah visualisasi lokasi sekitar kampung Tanjung Gedong untuk menstimulasi diskusi (Gambar 2). Proses akhir dilakukan dengan membuat formula pelatihan, dilanjutkan dengan memproduksi peta digital sebagai keluaran.

Proses awal pemetaan diinisiasi dengan kunjungan awal dan observasi untuk mengamati kampung Tanjung Gedong melalui perspektif dari dalam. Sudut perspektif ini merupakan bagian struktur kampung yang dialami sebagai pengalaman keruangan, baik bagi pengunjung (awam) maupun warga kampung itu sendiri. Sebuah pemetaan sederhana dibuat untuk memberikan sebuah sketsa untuk menentukan lokasi peta yang akan dibuat. Lokasi pemetaan terpilih adalah di area gerbang kampung Tanjung Gedong, karena berpotensi memberikan kesan pertama (first impression) bagi pengunjung, sementara memperlihatkan gambaran awal bagi pengalaman keruangan dalam kampung. Bagi warganya, pemetaan sekitar gerbang kampung merupakan sebuah pilot project pemetaan, lokasi transisi yang mempererat hubungan kampung dengan kotanya. Maka dari itu sebuah pemikiran logis dibangun untuk menentukan alasan pemilihan area yang dipetakan.

Pemilihan jalan Tanjung Gedong sebagai lokasi proyek pilot didasari oleh alasan-alasan berdasarkan hasil diskusi berikut:

1. Bentuk lintasan koridor yang lebih lurus memberikan kemudahaan dalam pemetaan, penyajian perspektif lebih baik dan tatanan yang lebih teratur untuk menginsisiasi.

2. Lokasi tidak berada pada lalu lintas ramai, sehingga memberi dukungan keamanan dan kenyamanan saat proses pelaksanaan.

3. Masjid Jami Al Taufiq adalah sebuah landmark kampung dan terletak tepat di area tersebut.

4. Situasi familiar, baik bagi pengunjung maupun warga kampung.

Memiliki mitra dan kenalan di lokasi tersebut, sehingga memudahkan kegiatan Abdimas dan sebagai antisipasi bila terjadi kondisi darurat 

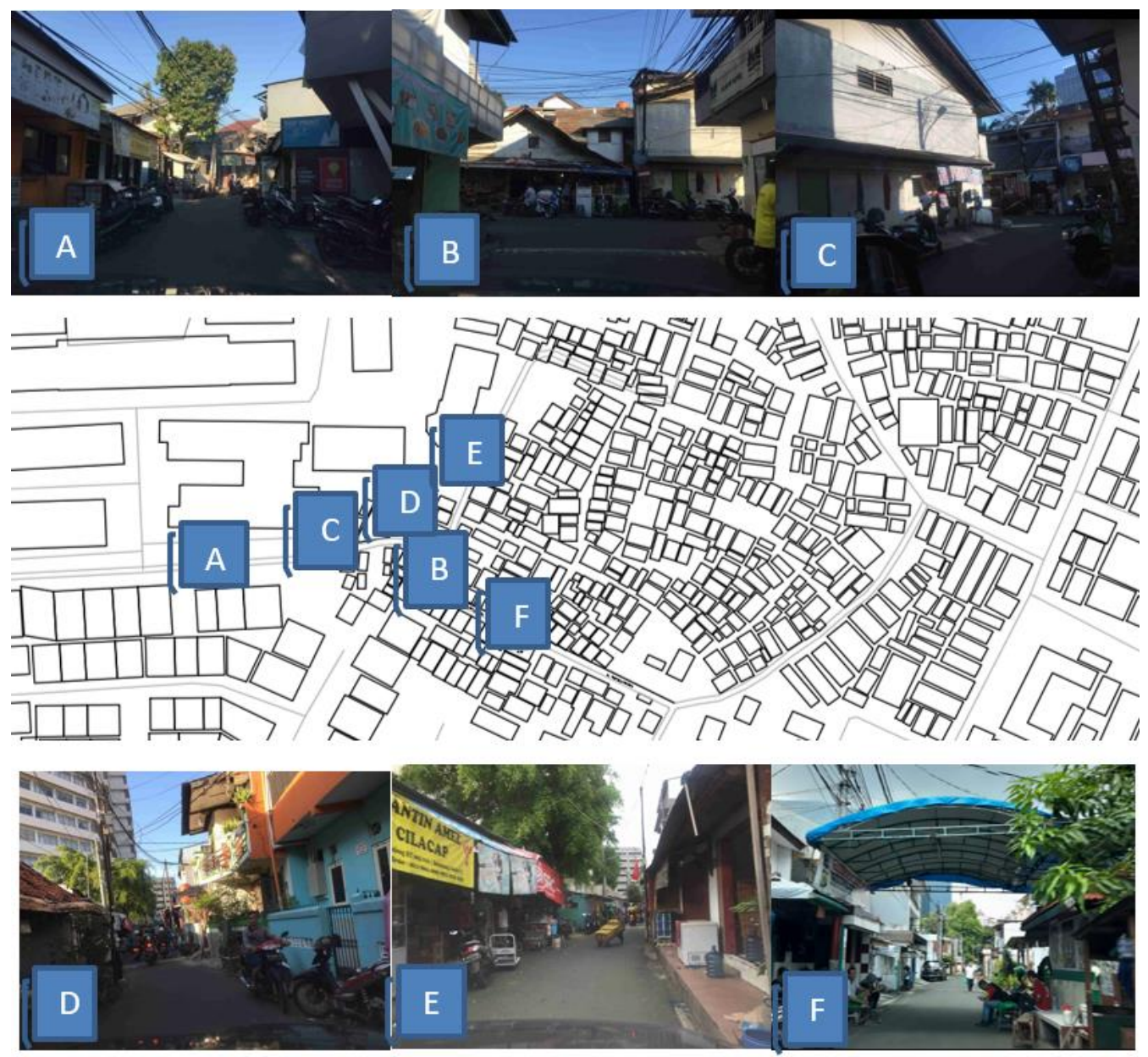

Gambar 2. Peta dan Foto Lokasi Sekitar Jalan Tanjung Gedong

Sumber: Tim PKM, 2020

Pada proses transisi, dokumentasi dilakukan sebagai data penggambaran. Rekaman dilakukan pada koridor jalan Tanjung Gedong dan sekitarnya. Tujuannya untuk mendapatkan perspektif dan tampak bangunan secara keseluruhan. Dengan dokumentasi, rekaman memberikan visualisasi pada kondisi area yang dipetakan. Pengukuran manual dilakukan dengan menggunakan alat ukur dan dicocokkan dengan proporsi anggota tubuh dan dimensi material. Dokumentasi visual pada struktur luar ini sekaligus mengurangi jumlah visitasi dan survey, sehingga privasi warganya tetap dapat terjaga. Visualisasi struktur luar kampung dilakukan dengan menghasilkan gambar peta berupa koridor. Namun untuk mendukung proses pencocokan pada detail peta, maka gambar frontal pada tampak bangunan juga disediakan. Kondisi kampung tidak sama dengan pemukiman real estate; pedagang kaki lima, parkir liar, tempat sampah maupun perkakas rumah tangga kerap ditemukan di sekitar lingkungan. Namun demikian keberadaan mereka merupakan bagian dari kealamiahan kampung, sehingga dalam proses pendokumentasian tidak disingkirkan atau dieliminasi. Gambar frontal kemudian dicocokkan sebagai data tambahan saat melakukan pemetaan.

Proses akhir pemetaan berfokus pada visualisasi kondisi fisik struktur berupa pemetaan yang berfokus pada koridor kampung. Proses ini dimulai dengan membuat sketsa berupa pola modul dari struktur kampung secara keseluruhan. Proses pemolaan sekaligus mengeliminasi elemen dekorasi dan ornamen yang bukan merupakan lingkup penggambaran. 
Setelah memperoleh sketsa keseluruhan secara proporsional, elemen struktur digambarkan secara rinci sesuai data yang diukur.

Setelah keseluruhan gambar struktur rampung, gambar ini dicocokkan kembali dengan foto. Sesuai dengan arahan tipologi yang mendefinisikan struktur luar sebagai struktur pembentuk karakter visual dan area kampung, tampak bangunan sebagai kulit luar atau pelingkup bangunan keseluruhan membantu dalam pemeriksaan kembali gambar pemetaan (Gambar 3).

Secara umum, kegiatan ini menghasilkan keluaran berupa pemetaan struktur luar di kampung Tanjung Gedong yang dilakukan dengan dua cara:

\section{A. Pemetaan Manual}

Dilakukan dengan sketsa melalui media pensil dan pen. Peta dibuat mengindahkan skala dan proporsi. Obyek penggambaran diukur berdasarkan dimensi material dan tubuh. Penggambaran dituangkan di atas kertas HVS dan digunakan sebagai bahan diskusi dan komunikasi.

Penggambaran peta manual dilakukan dengan tiga tahap yakni:

1) Sketsa umum.

Sketsa dibuat berdasarkan proporsi, komposisi dan bentuk keseluruhan pelingkup. Sirkulasi dan struktur dalam ditambahkan sebagai pelengkap.

2) Tracing map.

Pada gambar manual dilakukan dengan pen, untuk mempertajam dan memperbaiki garis. Pada gambar digital dilakukan dengan autodesk cad. Metode ini dikenal dengan nama lain metode penggambaran ulang.

3) Membuat Pola

Pola dihasilkan dengan menentukan patokan, arahan, hubungan pada peta. Formula gambar ditentukan berdasarkan komposisi untuk menentukan pola. Pola dikembangkan menjadi metode sehingga cara menggambar dapat dijelaskan logika pembuatannya.

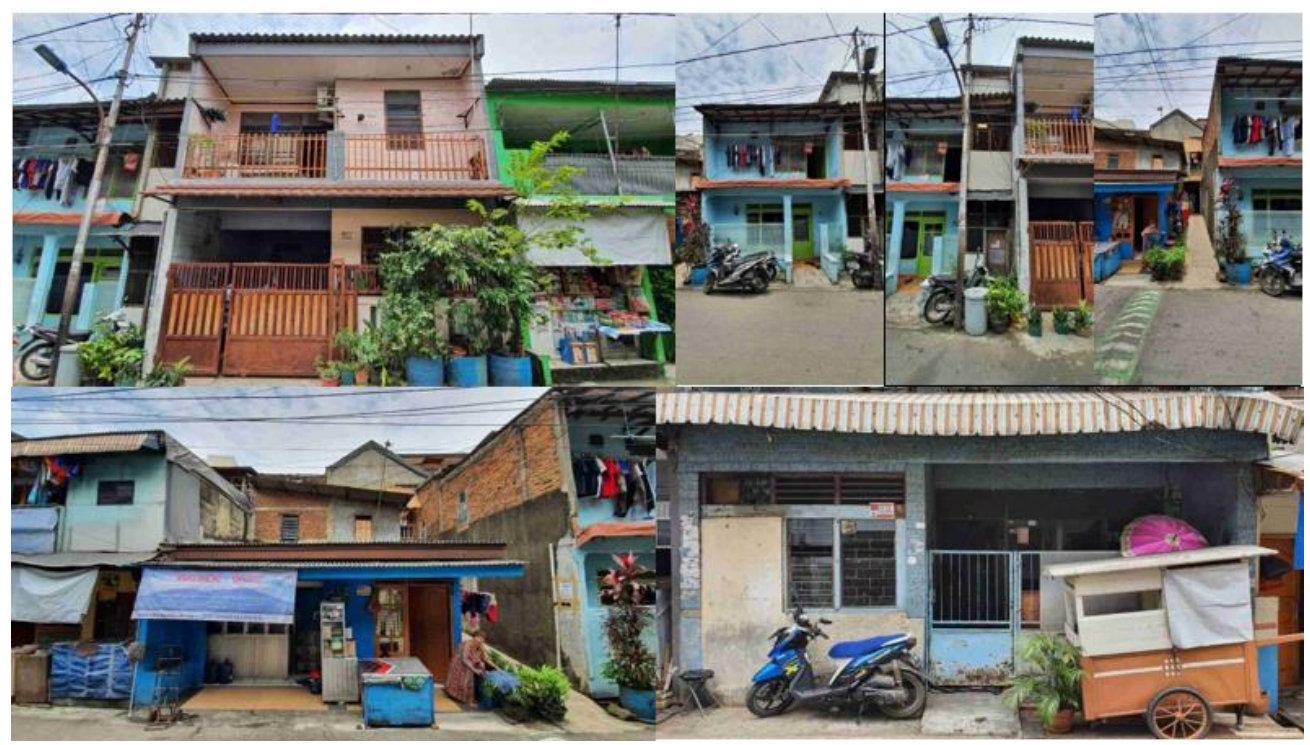

Gambar 3. Dokumentasi Suasana dan Struktur Luar Kampung Tanjung Gedong Sumber: Tim Abdimas, 2020. 


\section{B. Pemetaan Digital.}

Pemetaan dilakukan menggunakan autodesk cad. Penggambaran merupakan tracing dari sketsa manual. Dokumentasi tampak digunakan sebagai data tambahan untuk pemeriksaan kembali. Penggambaran dilakukan dengan menggunakan komputer dan dicetak sesuai keperluan. Pemetaan digital bertujuan utama untuk dokumentasi dan penyempurnaan dan aktualisasi peta eksisting.

Penggambaran peta digital dilakukan dengan cara:

1) Pencocokan peta digital yang tersedia.

Peta autodesk cad yang tersedia, dicocokkan dengan google map dan hasil observasi.

2) Pembuatan siluet struktur luar sesuai dengan observasi dan pengukuran.

Komposisi utama struktur luar yang terdiri dari siluet rumah dan koridor.

3) Tracing peta manual.

Penggambaran presisi untuk merinci struktur luar kampung.

4) Finalisasi pemetaan struktur luar.

Peta grafis struktur luar kampung.

Maka dari itu, dengan proses peta berbeda, kegiatan ini menawarkan dua tujuan spesifik. Sementara peta manual ditujukan terutama untuk pelatihan dan transfer keilmuan, peta digital efektif sebagai rekaman dan dokumentasi yang presisi (Gambar 4 dan Gambar 5).

\begin{tabular}{|c|c|c|c|}
\hline No & Waktu & Foto & Keterangan \\
\hline 1. & Jumat, 20 Maret 2020. & & $\begin{array}{l}\text { Penggambaran sketsa siluet struktur } \\
\text { luar dengan media pensil. }\end{array}$ \\
\hline 2. & Jumat, 20 Maret 2020. & & $\begin{array}{l}\text { Penyelesaian sketsa siluet struktur } \\
\text { luar dengan media pensil. }\end{array}$ \\
\hline 3. & Jumat, 20 Maret 2020. & & $\begin{array}{l}\text { Penyelesaian sketsa peta dengan } \\
\text { media pensil. }\end{array}$ \\
\hline 4. & Senin, 23 Maret 2020. & & $\begin{array}{l}\text { Penggambaran kembali dan koreksi } \\
\text { siluet struktur luar dengan media pen. }\end{array}$ \\
\hline 5. & Senin, 23 Maret 2020. & & $\begin{array}{l}\text { Penggambaran struktur luar dengan } \\
\text { media pen. }\end{array}$ \\
\hline 6. & Senin, 23 Maret 2020. & & $\begin{array}{l}\text { Penyelesaian sketsa peta dengan } \\
\text { media pen. }\end{array}$ \\
\hline
\end{tabular}

Gambar 4. Proses Pemetaan Manual dan Digital 


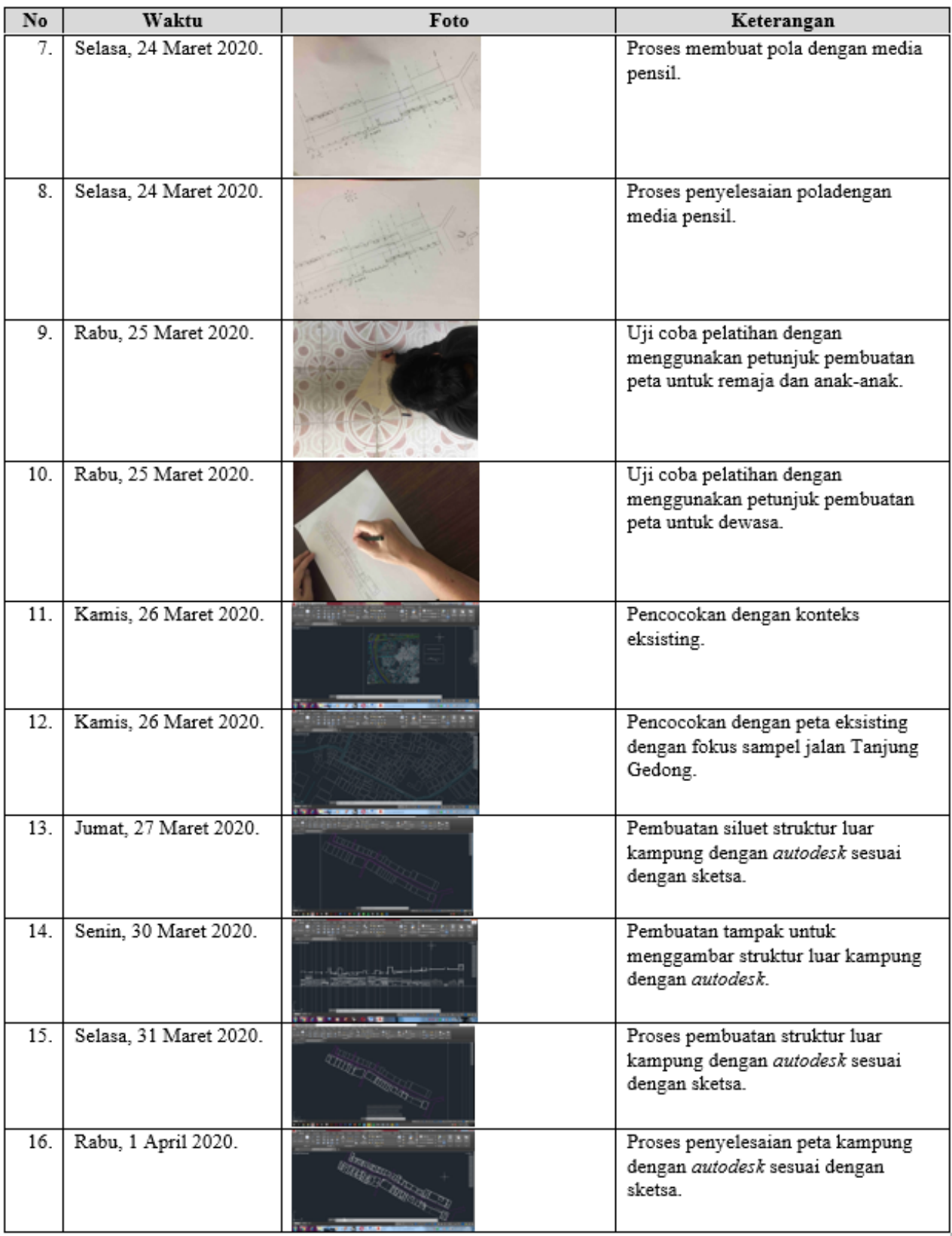

Gambar 5. Proses Pemetaan Manual dan Digital (lanjutan)

Hasil akhir pemetaan struktur pada dasarnya terbagi dua: peta manual dilakukan dengan sketsa manual untuk pelatihan membuat peta. Peta manual diturunkan menjadi dua gambar, yakni: contoh peta sebagai sampel dan pola peta sebagai rumusan atau cara membuat peta manual. Sementara sampel merujuk pada hasil akhir yang dituju, pola peta memberikan logika proporsi dan komposisi dalam proses membuat pemetaan (Gambar 6).

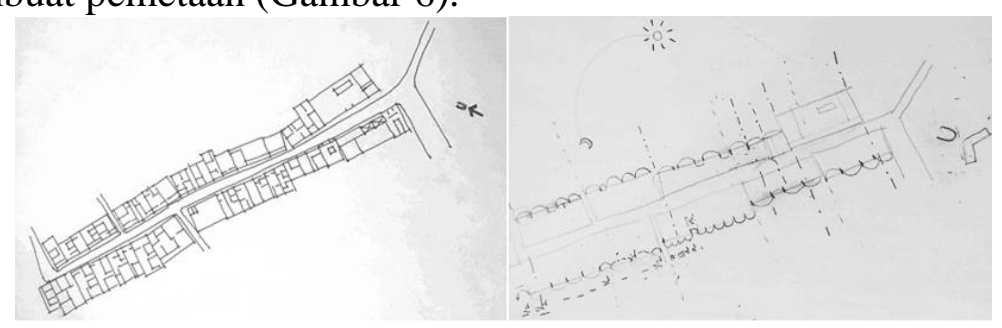

Gambar 6. Peta Manual dan Pola Peta Struktur Luar Kampung Tanjung Gedong Sumber: Tim Abdimas, 2020 
Peta digital dipresentasikan dalam bentuk file autodesk cad dalam bentuk gambar dan video pembuatan (Gambar 7). Tujuannya adalah sebagai dokumentasi dan simulasi membuat peta sebagai bahan tambahan pelatihan karena terjadi pandemi Covid-19. Pada proses pembuatan pemetaan digital, sketsa manual, foto lokasi, foto tampak dimasukkan ke dalam file autodesk cad untuk membantu metode tracing untuk menghasilkan keluaran peta struktur luar yang presisi.

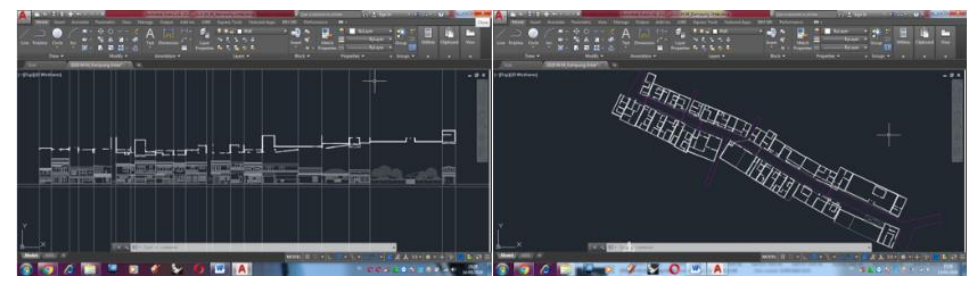

Gambar 7. Peta Digital Struktur Luar Kampung Tanjung Gedong

Sumber: Tim Abdimas, 2020

Ilustrasi peta adalah keluaran yang ditujukan sebagai sebuah presentasi. Peta digital disempurnakan secara grafis (Gambar 8). Visualisasi peta memberikan gambaran representatif dari situasi struktur luar kampung Tanjung Gedong pada konteksnya. Sampel peta digambarkan dengan struktur terbuka untuk mengkontras konteks. Dengan struktur terbuka, gesture lokasi pemetaan menstimulasi penekanan pada relasi antara rumah, koridor, kampung dan lingkungan sekitarnya. Sample pemetaan pada jalan Tanjung Gedong sekaligus mengaktualisasi peta sebelumnya.

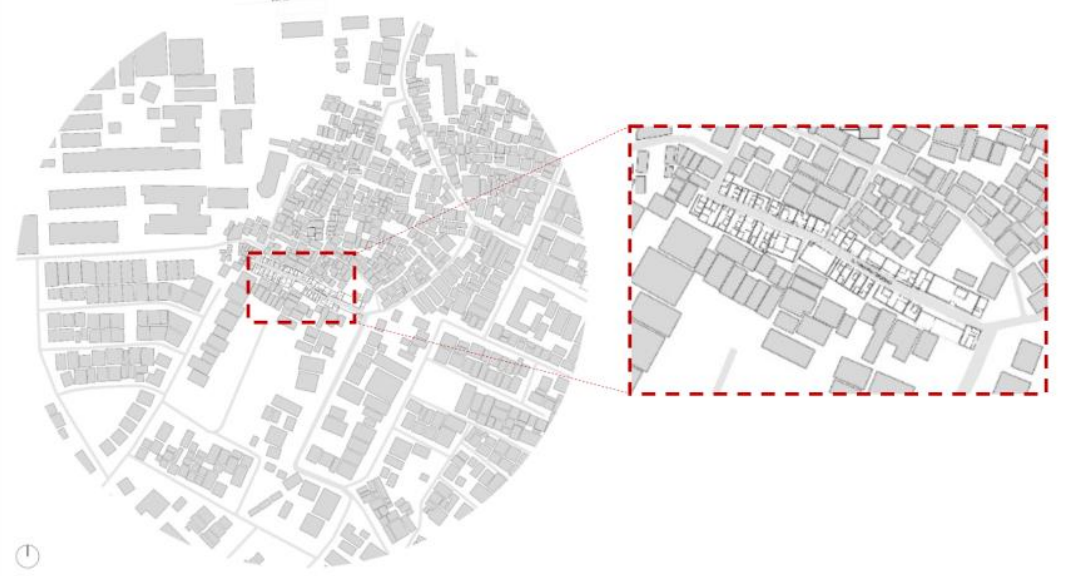

Gambar 8. Visualisasi Peta Struktur Luar Kampung Tanjung Gedong

Sumber: Tim Abdimas, 2020

\section{KESIMPULAN DAN SARAN}

Pemetaan struktur luar kampung Tanjung Gedong dilakukan dengan dua cara, yakni: 1) pemetaan manual yang efektif sebagai sarana transfer keilmuan, sementara; 2) pemetaan digital menghasilkan dokumentasi yang bersifat presisi untuk saling melengkapi. Alasannya agar pertukaran informasi dan pemeriksaan ulang dapat dilakukan saat proses penggambaran pemetaan. Proses pemetaan bersifat linear, sehingga mendukung pembelajaran keruangan dilaksanakan secara berurutan. Formula pembuatan peta menstimulasi partisipasi warga untuk mengenal keruangan melalui penggambaran. Pemetaan berfokus pada struktur luar sebagai proses inisiasi dan menghindari terganggunya privasi warga. Maka dari itu, pemetaan lanjutan dapat merekomendasi penggambaran struktur dalam yang lebih rinci, berupa: tampak maupun potongan lingkungan atau dapat juga melanjutkan pemetaan struktur luar pada lokasi yang lain. 


\section{Pengakuan}

Selama Pandemi Covid-19, tidak terdapat perubahan struktur luar kampung, namun demikian, perlu diakui Pandemi Covid-19 mempengaruhi produktivitas dan efektivitas pemetaan. Pemetaan manual dijadikan aktivitas pelatihan membuat peta, diadaptasikan menjadi media pembelajaran jarak jauh. Sementara pemetaan manual dijadikan sampel pembelajaran, pemetaan digital dikembangkan menjadi video simulasi. Informasi umum mengenai lokasi pemetaan yakni: pada awal April 2020, aktivitas di kampung Tanjung Gedong tetap berlangsung seperti biasanya, namun demikian menjelang tengah April 2020, intensitas lalu lalang telah berkurang jauh. Masjid Jami Al Taufiq sementara ditutup untuk aktivitas terbatas. Oleh karena situasi pandemi Covid-19, pemetaan struktur luar mengacu pada observasi yang dilakukan sebelum Pandemi. Untuk memperkuat analisa pemetaan struktur luar, tampak digunakan untuk membantu proses penggambaran struktur luar. Pemetaan ini juga menambahkan visualisasi lain yang bersifat ilustrasi pelengkap, yang hasilnya diperoleh dari proyeksi tampak dan kunjungan singkat saja.

\section{REFERENSI}

Ambarwati, W. \& Johan, Y., 2016. Sejarah dan Perkembangan Ilmu Pemetaan. Jurnal Enggano, $1(2)$, pp. $80-82$.

Darmawan, S. \& Utami, T. B., 2018. Pola Pemanfaatan Ruang Terbuka pada Pemukiman Kampung Kota. Vitruvian: Jurnal Arsitektur, Bangunan, dan Lingkungan, 7(3), pp. $127-$ 136.

Isnaini, N., 2015. Komparasi Penggunaan Media Google Earth dengan Peta Digital pada Materi Persebaran Fauna Kelas XI IPS di SMA Negeri 1 Semarang. Jurnal Geografi, 12(1), pp. $52-$ 61.

Maharani, S., Apriani, D. \& Kridalaksana, A. H., 2017. Sistem Informasi Geografis Pemetaan Masjid di Samarinda Berbasis Web. Jurnal Informatika, 11(1), pp. 9-20.

Samhudi, S., 2015. The Use of Mind Mapping Technique in Teaching Vocabulary. Getsempena English Education Journal, 2(1), pp. 80-92.

Setyawan, D., Nugraha, A. L. \& Sudarsono, B., 2018. Analisis Potensi Desa Berbasis Sistem Informasi Geografis. (Studi Kasus: Kelurahan Sumurboto, Kecamatan Banyumanik, Kabupaten Semarang). Jurnal Geodesi Undip, 7(4), pp. 1-7.

Sihombing, A., 2014. Drawing Kampung through Cognitive Maps Case Study: Jakarta. Science Direct APCBEE Procedia, Volume 9, pp. 347-353.

Siswanto, V. K. et al., 2018. Potential and Problems Participatory Mapping of Creative Industry in Kampong Dolly, Surabaya. Conf. Series: Earth and Environmental Science, Volume 202, pp. 1-8.

Siswanto, V. K., Aulia, B. U., Umilia, E. \& Hekmachtyar, I., 2018. Mapping and Arrangement of Development Strategy for Creative Industry of UMKM Kampong Dolly in Surabaya. Case Study: Fashion Small Industry. IOP Conf. Series: Earth and Environmental Science, Volume 202, pp. 1-7.

Wijaya, A., Agustini, E. P. \& Nardo, E., 2018. Sistem Informasi Geografis dalam Pemetaan Lahan Gambut di Kabupaten Musi Banyuasin. Jurnal Resti, 2(1), pp. 330-226. 